\title{
Effects of Early-Life Stress on Social and Anxiety-Like Behaviors in Adult Mice: Sex-Specific Effects
}

\author{
Natalya P. Bondar $\mathbb{D}^{1,2}$ Arina A. Lepeshko, ${ }^{1,2}$ and Vasiliy V. Reshetnikov ${ }^{1}$ \\ ${ }^{1}$ Laboratory of Gene Expression Regulation, Institute of Cytology and Genetics, Siberian Branch of the Russian Academy of Sciences, \\ 10 Prospect Lavrentyeva, Novosibirsk 630090, Russia \\ ${ }^{2}$ Novosibirsk National Research State University, 2 Pirogova Street, Novosibirsk 630090, Russia
}

Correspondence should be addressed to Natalya P. Bondar; nbondar@bionet.nsc.ru

Received 27 August 2017; Revised 18 November 2017; Accepted 5 December 2017; Published 9 January 2018

Academic Editor: Giuseppe Biagini

Copyright (c) 2018 Natalya P. Bondar et al. This is an open access article distributed under the Creative Commons Attribution License, which permits unrestricted use, distribution, and reproduction in any medium, provided the original work is properly cited.

\begin{abstract}
Stressful events in an early postnatal period have critical implications for the individual's life and can increase later risk for psychiatric disorders. The aim of this study was to investigate the influence of early-life stress on the social behavior of adult male and female mice. C57Bl/6 mice were exposed to maternal separation (MS, $3 \mathrm{~h}$ once a day) or handling (HD, 15 min once a day) on postnatal day 2 through 14 . Adult male and female mice were tested for social behavior in the social interaction test and for individual behavior in the plus-maze and open-field tests. Female mice exposed to maternal separation had increased social behavior and increased anxiety. MS male mice had no changes in social behavior but had significantly disrupted individual behavior, including locomotor and exploratory activity. Handling had positive effects on social behavior in males and females and decreased anxiety in males. Our results support the hypothesis that brief separation of pups from their mothers (handling), which can be considered as moderate stress, may result in future positive changes in behavior. Maternal separation has deleterious effects on individual behavior and significant sex-specific effects on social behavior.
\end{abstract}

\section{Introduction}

There is a wealth of data demonstrating that exposure to stressful events early in life can increase the risk for psychiatric disorders, including mood and anxiety disorders [1-4]. The neural basis of the consequences of early-life stress is poorly understood, and stressful events are supposed to cause structural and functional disturbances in brain regions responsible for emotional behavior in humans [5-7]. Adults with a history of mistreatment in childhood have reductions of medial prefrontal cortex volume [8], decreased hippocampal volume $[9,10]$, hyperactivity of the hypothalamicpituitary-adrenal axis [11], and an associated deterioration of sensory and cognitive functions [12]. Animal models of early-life stress also demonstrate disturbances in neuronal activities and brain plasticity [13-17].

Maternal separation (MS) is the most commonly used rodent model of early-life stress $[18,19]$. Separation of pups from their dams and nest for 3 or more hours once a day during the first two postnatal weeks produces increased anxiety-like behavior and exaggerated hypothalamicpituitary-adrenal (HPA)-axis responses to stress in adulthood as well as behavioral and cognitive disturbances [20-24]. These effects have well been studied in rats, while behavioral changes in MS mice remain inconsistent $[18,25]$.

Nevertheless, consequences of early-life stress in mice are significantly sex-biased. Maternal separation of pups from their dams generally increases anxiety in adult male mice [26-28], while females tend to have a stable anxiety level $[25,27,29,30]$. Few studies have found increased anxiety in adult female mice after early-life stress [28, 31]. Neither male nor female mice have changes in the level of depression in the forced swim test $[25,26,32-34]$. In mice, MS in combination with restraint stress for mothers during pup separation enhanced the expression of depressive symptoms in the form of decreased sucrose solution preference in both male and female offspring [29]. If maternal separation was combined with early weaning, the authors observed 
persistent behavioral disturbances in male mice, including enhanced anxiety-like behavior and depressive behavior [35-37]. Apparently, mice require more stress to attain changes in emotion-related behavior and stress reactivity similar to those in rats [25].

In humans, psychiatric disorders such as depression and anxiety are highly comorbid with social dysfunction, and disturbances in social behavior generally appear before these disorders. Therefore, studying dysfunctional social interactions is important for understanding the development of the stress response [38]. However, the influence of maternal separation on social behavior is poorly studied. Studies on males usually find no changes in social behavior in mice [39-41] and rats [42, 43]. A small proportion of the studies reports either slightly intensified social interaction in male mice [29] or, the other way round, decreased social behavior [44] under the influence of early-life stress. Female studies are few, and they provide inconsistent observations: some state that maternal separation results in decreased time investigating other mice [31], while others suggest that it has no effect on social behavior [29]. Thus, effects of early-life stress on adult social behavior remain evasive, especially in their sex-specific aspect.

Interestingly, brief separation of rat pups from their dams (10-15 min per day) often has an opposite effect on later behavioral and stress-related responses compared to prolonged separation $[21,22,45]$. Some mouse studies show decreased anxiety and increased exploratory activity in males $[46,47]$ and none of these effects in females $[25,30]$. The influence of brief separation in early life on mouse social behavior has not yet been investigated.

Here, we attempt to characterize the effects of early-life stress on the social behavior of adult male and female mice and to see if there are correlations between changes and disturbances of individual behavior. A brief (15 min/day) and a prolonged separation ( $3 \mathrm{~h} /$ day) paradigm were used to identify possible positive and negative consequences of early-life adversity.

\section{Materials and Methods}

2.1. Animals. C57BL/6J mice were housed in the Center for Genetic Resources of Laboratory Animals (RFMEFI61914X0005 and RFMEFI62114X0010), Institute of Cytology and Genetics, the Siberian Branch of the Russian Academy of Sciences, Novosibirsk, Russia. The animals were housed under standard conditions (12:12 h light/dark cycle, lights on at 8.00 a.m.; feed pellets and water were available ad libitum). All procedures were approved by the Ethics Committee of the Institute of Cytology and Genetics SB RAS (Protocol number 25, December 2014) in conformity with EU Directive 2010/63/EU for animal experiments.

2.2. Maternal Separation. Virgin males and females were used for mating. Pregnant females were individually housed with paper nesting material during their third week of gestation. Only litters containing 4-6 pups were used for experiments. All stress procedures were carried out from 1 to $4 \mathrm{pm}$, in the light phase of day. Offspring were separated from dams on PND 2 through PND 14 (the day of birth was PND 0). At first, each dam was removed from her home cage and placed into a clean cage. Pups were then removed from its home cage and placed together into a small box filled with bedding (one litter for one box). After that, the dam was placed back into the home cage. In the brief separation condition [handling (HD)] the pups were separated from their dams for $15 \mathrm{~min}$ once a day, while at the prolonged separation [maternal separation (MS)], the pups were separated for 180 min once a day. The temperature in the MS cages was kept at $31 \pm 2{ }^{\circ} \mathrm{C}$ using infrared heat lamps to prevent thermoregulatory distress. No heat lamps were used on HD pups. The control pups were not separated from their dams. All cages were cleaned on a weekly basis. After weaning on PND 30, the offspring were housed in sibling groups of 2 to 4 animals of the same sex under standard housing conditions. Experimental groups consisted of 27 males (11 control, 10 $\mathrm{HD}$, and $6 \mathrm{MS}$ ) and 25 females (11 control, $6 \mathrm{HD}$, and 8 MS), each group included mice from at least three litters. The behavioral tests were conducted on PND 85-PND 110 in the following order: plus-maze, open-field, and the social interaction test (one test per day). $24 \mathrm{~h}$ after the last behavioral test, the animals were euthanized and the adrenal glands and thymus were removed and weighted. Schema of the experiment was presented on Figure 1(a).

\subsection{Behavioral Tests}

2.3.1. Plus-Maze Test. The elevated plus-maze test was performed according to the established procedure $[48,49]$. The maze consisted of two opposite open arms $(25 \mathrm{~cm} \times 5 \mathrm{~cm})$ and two opposite enclosed arms $(25 \mathrm{~cm} \times 5 \mathrm{~cm} \times 15 \mathrm{~cm})$ and had an open roof. The maze was set at $50 \mathrm{~cm}$ above the floor. All measurements were made in a dimly lit experimental room. The test apparatus was thoroughly cleaned between tests with different animals. During a 5 min test period, the following parameters of anxiety-like behavior were recorded: the percentage of entries into the open arms, closed arms, and central platform and the percentage of time spent in the open arms, closed arms, and central platform. These parameters were reported as the percentage of total entries and the percentage of testing time, respectively. The additional parameters were the latency of the first exit from the central platform, the number of head-dips, and the number of passages from one closed arm to another.

2.3.2. Open-Field Test. The open field (OF) consisted of a square arena $(80 \mathrm{~cm} \times 80 \mathrm{~cm})$ with a white floor and $25 \mathrm{~cm}$ high walls. The arena was brightly illuminated and had a central zone $(40 \mathrm{~cm} \times 40 \mathrm{~cm})$ and a peripheral zone (anywhere between the central zone and the walls). Each mouse was placed individually in the central zone, and the following behavioral parameters were recorded during a $5 \mathrm{~min}$ test period: the total distance traveled; the latency of the first exit from the central zone; the number of visits to the central zone; the time spent in the central and the peripheral zone; the number of rearing and self-grooming episodes; and total activity state (activity level of mouse was determined by the software as a function of pixel changes, EthoVision XT 


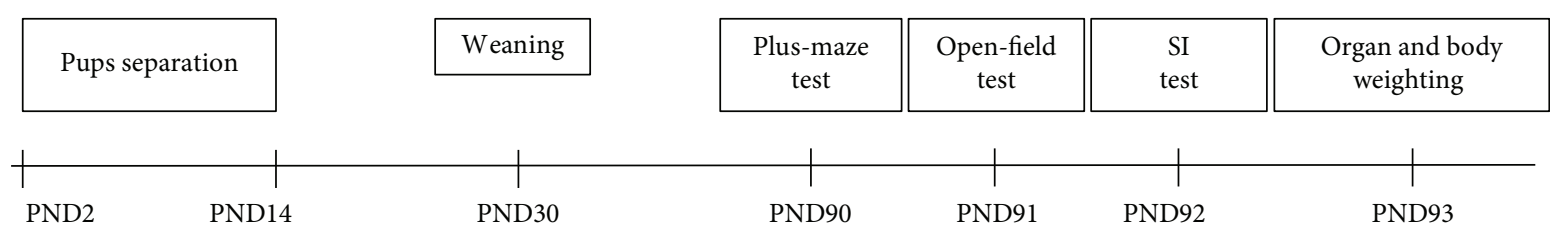

(a)

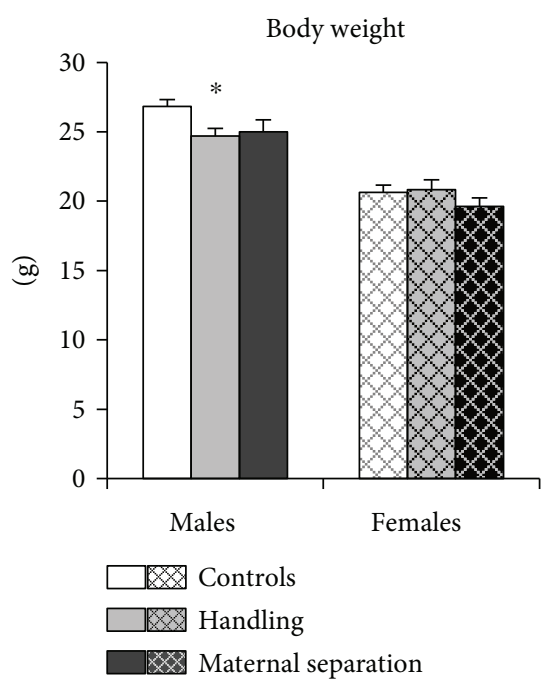

(b)

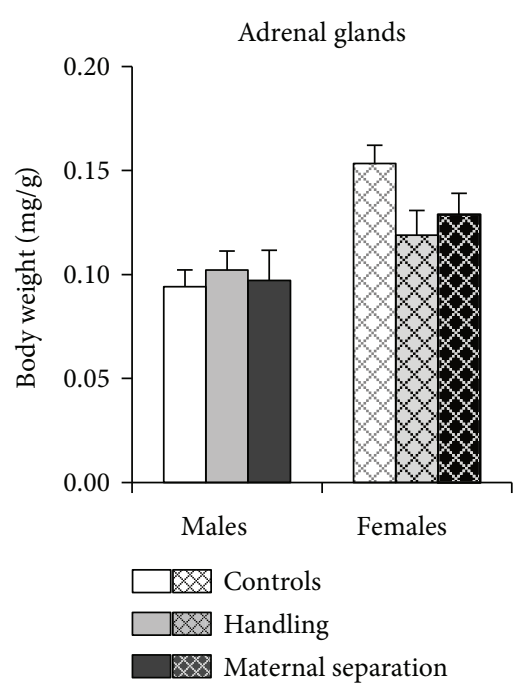

(c)

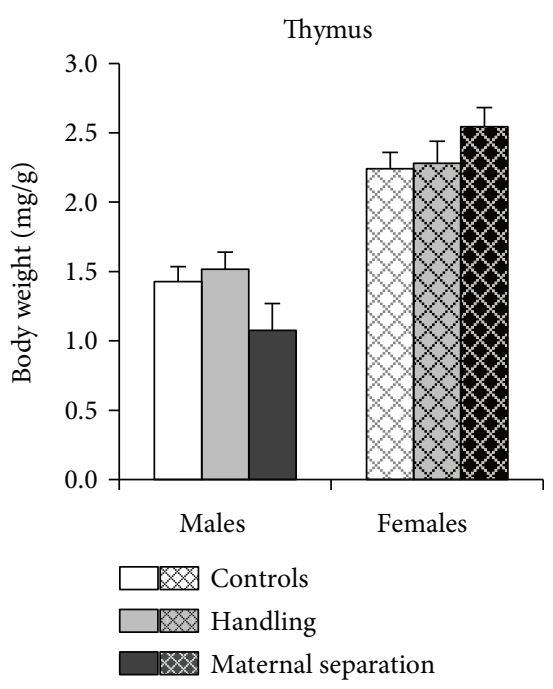

(d)

Figure 1: Timeline of the experiment (a), weights of the body (b), relative weights of adrenal glands (c), and thymus (d) in adult male and female mice. Handling decreased the weight of the body in males but not females. Females have the only tendency to reduce relative adrenal weight under early postnatal stress. Relative weights of adrenal glands and thymus are shown as organ weight in mg per gram of body weight. Data present as mean \pm standard error of the mean (SEM). White box: controls (males $n=11$, females $n=11$ ); grey box: HD (males $n=10$, females $n=6$ ), black box: MS (males $n=6$, females $n=8$ ); open columns: males; cross-hatched columns: females. ${ }^{*} p<0.05$ compared to controls.

threshold for activity- $0.2 \%$ ). The OF arena was thoroughly cleaned between tests with different animals.

2.3.3. Social Interaction Test. A square plastic arena $(40 \mathrm{~cm} \times 40 \mathrm{~cm} \times 25 \mathrm{~cm})$ was used for the social interaction test. A small perforated plastic target box $(10 \mathrm{~cm} \times 10 \mathrm{~cm})$ was placed near the center of one of the walls. The test consisted of two trials ( $5 \mathrm{~min}$ each). At the beginning of each trial, an experimental mouse was placed in the zone opposite to the target box, face to the wall. In the adaptation trial, the target box was empty and the animal was habituated to the novel environment for $5 \mathrm{~min}$. In the interaction trial, an unfamiliar partner of the same sex was placed into the target box and the reaction of the experimental mouse to the social target was investigated. Between the trials, the mouse was placed to a neutral cage. The following parameters were recorded during each trial: the total distance traveled, the number of visits to the interaction zone (a $5 \mathrm{~cm}$ zone around the target box), the time spent in the interaction zone, and the latency of the first contact with the target box. The interaction ratio was calculated as $100^{*}$ (time in the interaction zone, partner present)/(time in the interaction zone, partner absent).

2.4. Characterization of Estrous Phase. Vaginal smears from each female were taken every day after behavioral tests to determine the phase of the estrous cycle. Based on vaginal cytology, females were divided into two groups: diestrous (those in diestrus and metaestrus) and estrous (those in estrus and proestrus).

2.5. Statistical Analysis. All tests were videotaped and manually scored by the free open-source software BORIS (Behavioral Observation Research Interactive Software, http://www.boris.unito.it) [50]. The distance traveled in the OF test was scored using EthoVision XT v.10.0 (Noldus Information Technology, Netherlands).

Normal distribution and homogeneity of variances were tested using Shapiro-Wilk's and Levene's tests, respectively. As most behavioral data were not normally distributed, nonparametric tests were used. The statistical analysis of behavioral data was performed using Kruskal-Wallis one-way ANOVA, with the type of stress as a factor separately for males and females. Pairwise comparisons were performed by the Mann-Whitney $U$ test. The statistical significance threshold was set at $p<0.05$.

\section{Results}

3.1. Body, Adrenal Glands, and Thymus Weight. Males had more body weight and less relative weights of adrenals and thymus than females (effect of sex: for body weight $H(1,52)=18.8, p<0.001$; for adrenals $H(1,52)=29.1$, 
$p<0.001$; for thymus $H \quad(1,52)=35.9, \quad p<0.001)$ (Figure 1). Early postnatal stress has an effect on body weight in males $(H(2,27)=6.8, p=0.03)$; in HD males, the body weight is reduced in comparison with the control $(p=0.017)$, and MS males also have a tendency to reduce the body weight $(p=0.0841)$. Females have the only tendency to reduce relative adrenal weight under early postnatal stress $(H(1,19)=3.3, p=0.069)$.

3.2. Plus-Maze Behavior. Generally, males were less anxious than females (more time spent in open arms $(H(1$, $52)=6.6, p=0.01)$ and center $(H(1,52)=19.9, p<0.001))$ and have higher locomotor activity than females (more total number of entries $(H(1, N=52)=15.9, p=0.0001)$; more passages $(H(1, N=52)=6.2, p=0.0126))$.

Early-life stress had no effect on plus-maze behavior in male mice (Figure 2). However, stress in early life led to significant anxiogenic effect in MS females. MS females had increased latency to exit the central platform compared with controls (effect of stress: $H(2,24)=9.9, p=0.007$; MannWhitney $U$ test: $U=8, p=0.006)$ and spent less time in the open arms than controls (effect of stress: $H(2,24)=8.6$, $p=0.013$; Mann-Whitney $U$ test: $U=16, p=0.041)$ and HD mice $(U=3, p=0.01)$. Stress has a weak effect on the number of entries into the closed (a trend, $H(2,24)=5.1$, $p=0.077)$ and open (a trend, $H(2,24)=5.1, p=0.077)$ arms. Nevertheless, the percentage of entries into the open arms was decreased $(U=17, p=0.05)$ and the percentage of entries into the closed arms was increased $(U=17$, $p=0.05)$ in MS females compared to controls. Anxious effect was not caused by a decrease in locomotor activity of females (total entries, $p>0.05$ ), and MS females even had a higher number of passages between the closed arms compared to controls ( $U=12.5, p=0.018)$. HD females had only increased latency to exit the central platform compared with controls $(U=11.5, p=0.031)$.

Females were grouped by the phase of the estrous cycle to assess its effect on plus-maze behavior. However, an insufficient number of mice in each phase does not allow a correct statistical analysis. MS females tended to have increased anxiety both in estrus and diestrus (Figure 3).

3.3. Open-Field Behavior. Males have higher locomotor activity than females (longer distance travelled: $H(1,52)=17.8$, $p<0.001$, higher total activity: $H(1,52)=24.7, p<0.001)$ and more often go to the central zone $(H(1,52)=9.3$, $p=0.002$ ), indicating that males are less anxious than females in $\mathrm{OF}$.

3.3.1. Males. In the OF test, maternal separation had the greatest effect on the locomotor and exploratory activities of animals (Figure 4). Stress had an influence on total activity $(H(2,27)=6.5 ; p=0.038)$; parameters reflecting any movements of mice and the total activity of MS males were lower than in the control $(U=7.0 ; p=0.031)$ and HD group $(U=3.0 ; p=0.016)$. Decrease in activity is accompanied by decreasing distance travelled (stress effect: $H(2,27)=5.0$; $p=0.083 ; U=9.0 ; p=0.05$ compared to control; $U=6.0$; $p=0.048$ compared to the HD group). The MS group has less the duration of rearing $(H(2,27)=8.6 ; p=0.013$; $U=8.0 ; p=0.04)$ than the controls that reflects a decrease exploratory activity under prolonged postnatal stress.

Brief postnatal stress (handling) has an effect, mainly, on anxiety-like behavior. The number of visits (effect of stress: $H$ $(2,27)=5.6 ; p=0.062 ; U=28.5 ; p=0.022)$ and time spent in the central zone (effect of stress: $H(2,27)=5.2 ; p=0.075$; $U=25.0 ; p=0.013)$ in the HD group were increased to compare with controls, reflecting a slight decrease in anxiety. Moreover, the duration of rearing were decreased in the $\mathrm{HD}$ groups compared to controls $(U=23.0 ; p=0.009)$, as in the MS group. Parameters of locomotor activity were unchanged in the $\mathrm{HD}$ group.

3.3.2. Females. The analysis did not reveal any significant differences between groups (Figure 4). Estrous phase did not influence behavior in the $\mathrm{OF}$ test. However, diestrous HD females were slightly more anxious than MS females (Figure 5).

3.4. Social Interaction Test. Social interaction test assesses the level of sociability, which is measured by comparing the time a mouse spends in an interaction zone with a social target to the time in that zone in the absence of a social target. Males spend more time than females in the interaction zone both with an empty box and with a social target (effect of sex: $H(1,52)=6.2, p=0.012 ; H(1,52)=4.6, p=0.033$, resp. $)$.

3.4.1. Males. Behaviors in an adaptation trial of the SI test, when a mouse can investigate a new place, confirm the decline locomotor and exploratory activities in the MS group. MS males covered significantly less distance than controls (effect of stress: $H(2,27)=5.5, p=0.064 ; U=8.0 ; p=0.042$ ) and HD males $(U=4.0 ; p=0.024)$ (Figure 6). The number of rearing was lower in MS males than in controls (effect of stress: $H(2,27)=8.1, p=0.017 ; U=4.0 ; p=0.012)$ and HD males $(U=0.5 ; p=0.006)$.

In the interaction trial, when an unknown mouse was introduced into the small box, all groups had increased time spent in the interaction zone (interaction score $>100 \%$, Figure 6). A significant effect of stress was revealed on the time spent in the interaction zone $(H(2,27)=8.1, p=0.018)$; $\mathrm{HD}$ males spent more time responding to the social target than controls $(U=30.0 ; p=0.03)$. The MS group did not differ from controls and the HD group.

3.4.2. Females. Early-life stress has no significant effect on behavioral parameters in the adaptation trial. In the interaction trial, all groups had increased time spent in the interaction zone when a partner was presented (interaction score $>100 \%$, Figure 7). Surprisingly, the interaction scores in HD and MS females were higher than in controls (effect of stress: $H(2,25)=10.3, p=0.006 ; U=8.0 ; p=0.012$ and $U=11.0 ; p=0.006$, resp.), indicating that both stressed females groups increased sociability. MS females have enhanced not only score but also time spent near the social target compared to controls (effect of stress: $H(2,25)=4.7$, $p=0.096 ; U=17.0 ; p=0.026)$. And, apparently, this increased sociability led to an increase in the distance traveled in MS females compared to controls (effect of stress: $H(2,25)=6.0, p=0.049 ; U=17.0 ; p=0.026)$. 

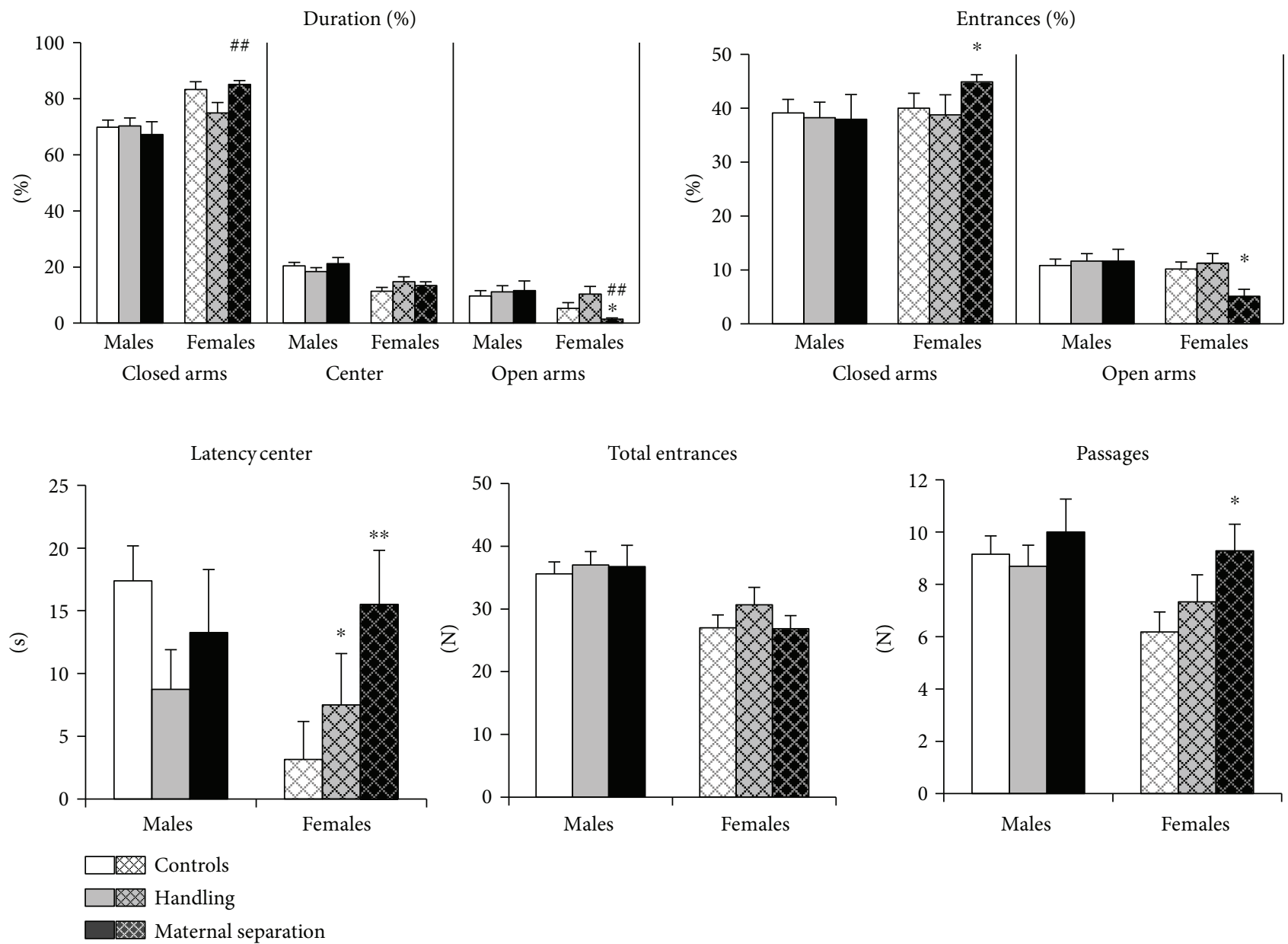

FIGURE 2: Effects of early-life stress on the behavior of adult mice in the plus-maze test. Early-life stress had no effect on plus-maze behavior in male mice but led to significant anxiogenic effect in MS females. Data present as mean \pm standard error of the mean (SEM). White box: controls (males $n=11$, females $n=11$ ); grey box: HD (males $n=10$, females $n=6$ ), black box: MS (males $n=6$, females $n=8$ ); open columns: males; cross-hatched columns: females. ${ }^{*} p<0.05,{ }^{* *} p<0.01$ compared to controls; ${ }^{\# \#} p<0.01$ compared to HD.

Figure 8 shows behavioral parameters depend on estrus and diestrus. There was only one estrous HD female in the test, which complicated the statistical analysis of the estrous cycle.

\section{Discussion}

Our study focused on the effects of maternal separation on the social behavior of adult mice and compared changes with changes in individual behavior. We showed that early postnatal stress had different effects on males and females.

The study of individual female behavior in the MS group revealed significantly increased anxiety in the elevated plus maze. Females avoided the open arms of the maze, but their locomotor activity was the same as that of controls. The OF test also did not reveal changes in the locomotor activity of MS females. In contrast to females, MS male anxiety in our experiments remained unchanged. The lack of MS effect on male emotional behavior was accompanied by changes in locomotor and exploratory activity. The OF test showed a significantly less distance traveled and reduced total and exploratory activity. Moreover, less distance was covered in the SI test during the adaptation trial, when the mice explore a new field without any additional social stimulus. So we have found gender-specific influence of prolonged maternal separation on anxiety and locomotion. There are few works in which both males and females of the C57BL6 mice were simultaneously studied. Some of them found the same effects of MS on anxiety in males and females [28, 30], whereas one study revealed sex-specific influence on anxiety [27], but different from our results. Various results can be explained by the differences in methodology of maternal separation. So, for example, in the study of Romeo and colleagues [27], separated pups were kept at the ambient temperature of the vivarium during 3 hours without additional heating that can lead to a pup's hypothermia. Some of the works used sexually experienced females (having two or three litters before) $[25,30]$. Procedures for checking health and gender of pups as well as culling the pups at first postnatal day are stress factors for dams and pups and can affect results of the experiment [28]. So, minor differences in methodological aspects lead to a significant disagreement in the results. 

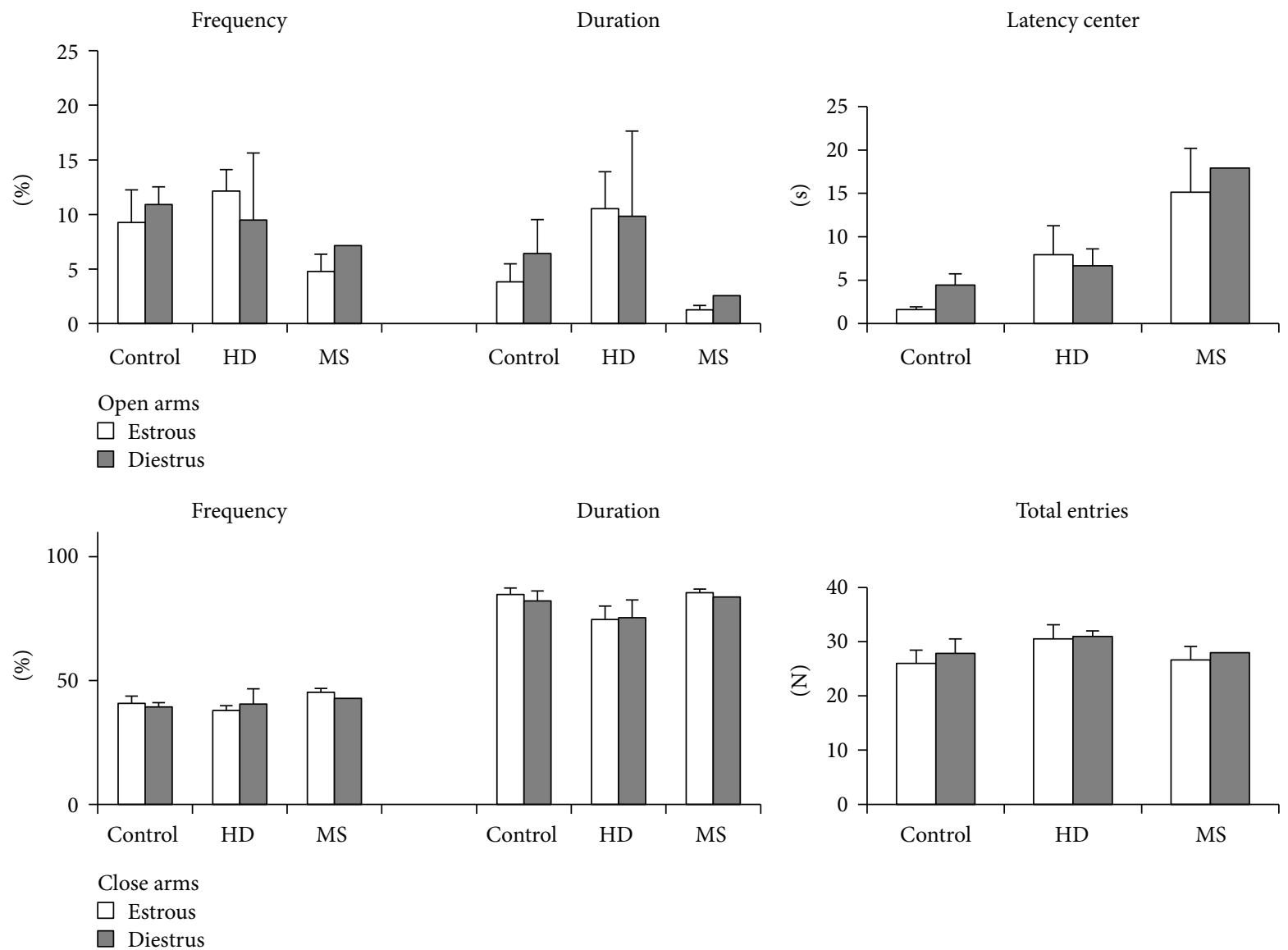

Figure 3: The influence of early-life stress on the behavior of adult female mice in plus-maze test in different phases of estrous cycle. Data present as mean \pm standard error of the mean (SEM). White box: estrous ( 5 female controls, 4 HD group, and 6 MS group), gray box: diestrus (6 female controls, $2 \mathrm{HD}$ group, and $1 \mathrm{MS}$ group). Insufficient number of mice in each phase did not allow a correct statistical analysis.

These disagreements and other inconsistent results $[31,32,51-55]$ suggest that effects on anxiety in mice are highly variable and depend even on small variations in environmental conditions during the postnatal period. Similarly, Millstein and Holmes [25] have concluded that repeated postnatal MS did not produce clear changes in anxiety- or depression-related behaviors in any of the five mouse strains studied. However, even in the lack of MS effects on behavior, it may alter the feedback regulation of response to a subsequent stress event, for example, resulting in a more pronounced and prolonged elevation of corticosterone levels [56-58] or a greater decrease in GR expression in the frontal cortex and hippocampus $[59,60]$.

The study of social behavior revealed somewhat unexpected results in females with prolonged maternal separation. The social interaction test showed increased sociability in MS females: the females responded to a novel conspecific more actively than the controls. However, this is not consistent with a high level of anxiety observed in females given the plus-maze test. High anxiety normally inhibits exploratory or social activity in animals. Here, we can hypothesize that the adaptation trial, during which the animals are familiarizing themselves with the experimental field, reduces anxiety. As is known, animals in familiar situations are less anxious and tend to have longer social contacts [61]. Additionally, longer testing decreases the fear of new space and stimulates exploratory behavior $[62,63]$. As is known, anxiety in new, unfamiliar situations ("state" anxiety) does not necessarily correlate with anxiety shown in familiar situations ("trait" anxiety) [64, 65]. Some kinds of stress, for example, repeated aggression experience, induce enhanced anxiety [66] as observed in the plus-maze together with enhanced exploratory activity towards a new neutral stimulus [67]. It is possible that early-life stress in MS females increases "state," but not "trait" anxiety, and that these females, when in a familiar situation, can display a high level of social behavior. However, this hypothesis requires scrutiny.

Interestingly, in contrast to females, the social behavior of adult males was absolutely unaffected by prolonged maternal separation, and the level of reaction to the presentation of another mouse remained the same as in controls, which is consistent with some other social behavioral studies in males $[39,40]$.

Thus, in our experiment, separating the pups from their dams for 3 hours in an early postnatal period has a pronounced sex-specific effect on both social and individual mice behavior. Females are more sensitive to 

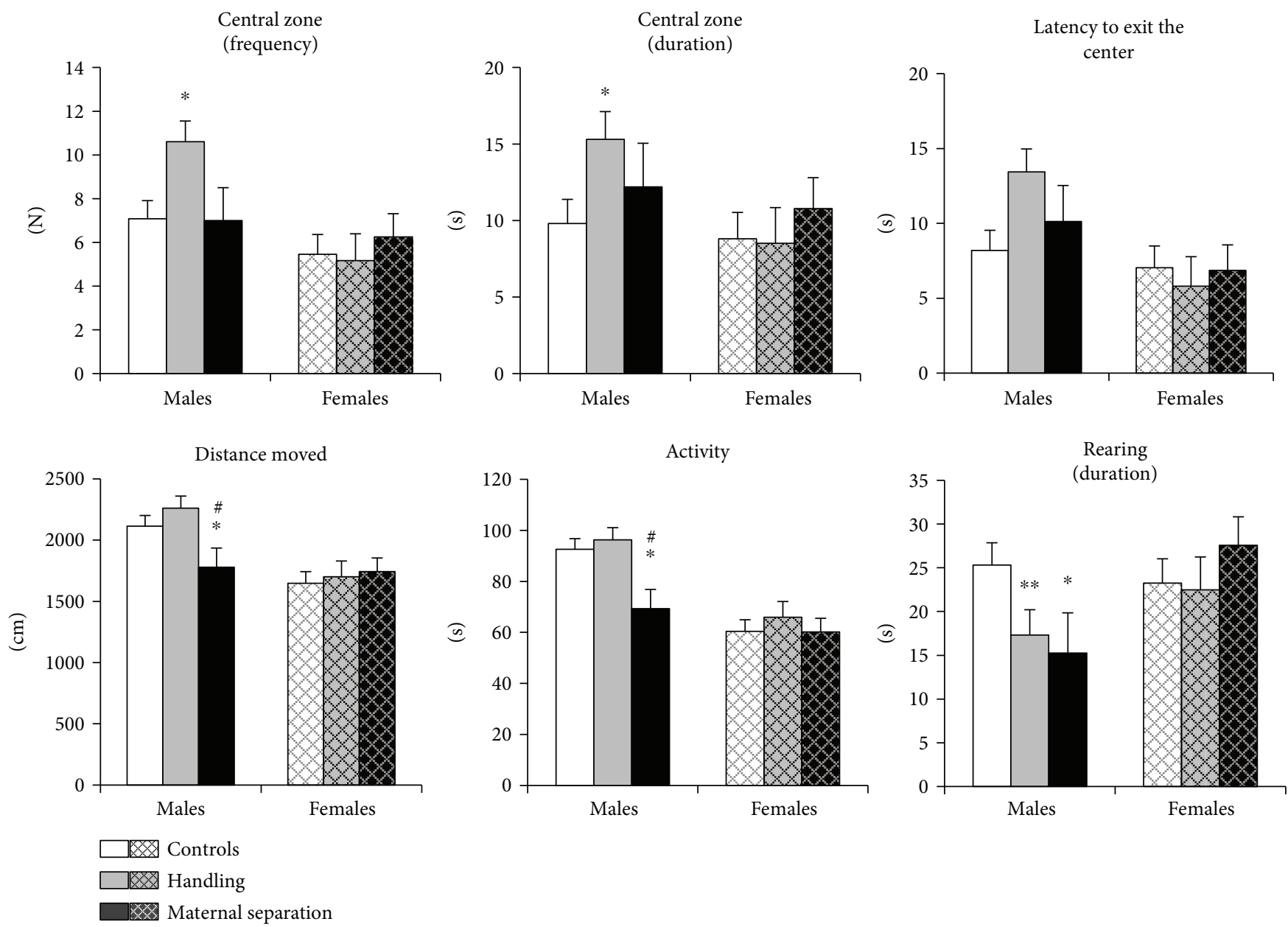

FIGURE 4: Effects of early-life stress on the behavior of adult mice in the open-field test. Male mice showed decreased locomotor and exploratory activities of MS males and decreased anxiety-like behavior in HD males. Females did not show the behavioral changes in the test. Data present as mean \pm standard error of the mean (SEM). White box: controls (males $n=11$, females $n=11$ ); grey box: HD (males $n=10$, females $n=6$ ), black box: MS (males $n=6$, females $n=8$ ); open columns: males; cross-hatched columns: females. ${ }^{*} p<0.05,{ }^{* *} p<0.01$ compared to controls; ${ }^{*} p<0.05$ compared to HD.

stress than males, and maternal separation has contrasting effects (increased anxiety versus increased sociability) on the former.

Results of rat experiments demonstrated that brief maternal separation, or handling, which can be considered moderately stressful for pups, can result in positive behavioral changes and even tolerance to more intensive stress $[21,22,45,56,68]$. In our experiment, we also have found a positive effect of handling-HD males demonstrated a decreased anxiety in the OF test and increased sociability in the SI test. Males were not afraid of visiting the central part of the open field and spent more time there than the controls or the MS group, and HD males also spent more time in the interaction zone when the unknown partner was presented. Brief separation of females had no effect on anxiety or individual and exploratory behavior but also an increased level of sociability-HD females had the highest interaction score, which reflects the difference between a reaction to a partner and a reaction to an empty box. There are few works on the impact of handling on subsequent behavior of adult mice. Unlike rat studies, the vast majority of studies of HD stress have not found significant changes in anxiety or individual behavior in male and female C57BL6 mice [25, 30, 69]. Only one study has found decreased anxiety in male mice induced by brief separation [46], which is similar to our results. Our study has shown for the first time, to our knowledge, that brief maternal separation may positively affect social behavior in mice. Both males and females showed increased sociability in the form of a more active reaction to the same-sex partner in the social interaction test.

Our study has shown that female mice have more pronounced positive and negative consequences of both maternal separation and neonatal handling compared to their male conspecifics. Compared to male rodents, female rodents are known to have greater corticosterone release under basal conditions [70] and in response to stress [71-74]. Female mice were shown to be more sensitive to unpredictable chronic mild stress [75], subchronic variable stress [76], and even acute stress [77]. Also, females have longer consequences of social defeat stress than males $[78,79]$. These findings explain the higher sensitivity of females to early-life stress consequences. 
Central zone

(frequency)

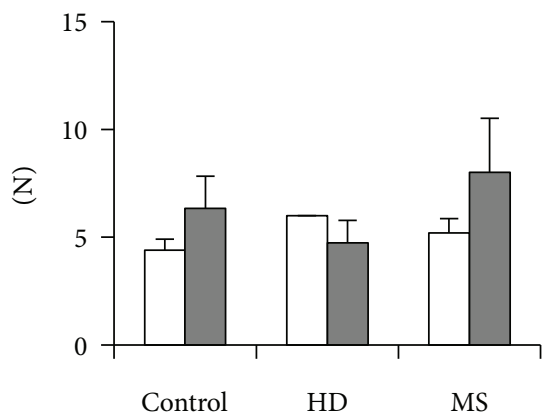

Distance covered

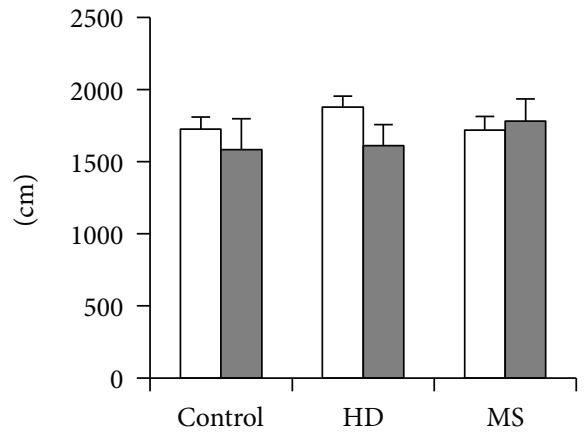

Central zone

(duration)

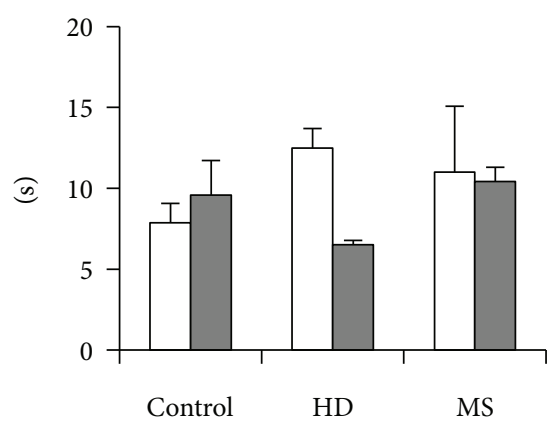

Activity

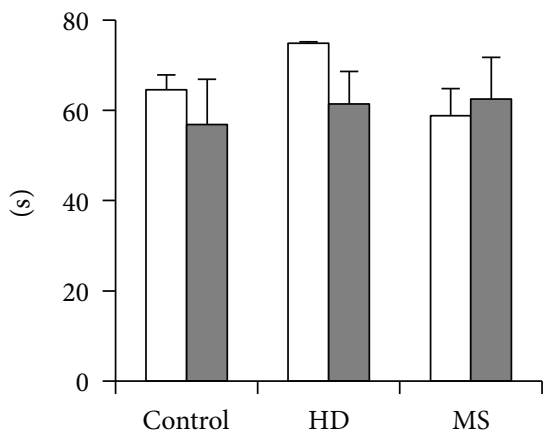

Latency of exiting the central zone

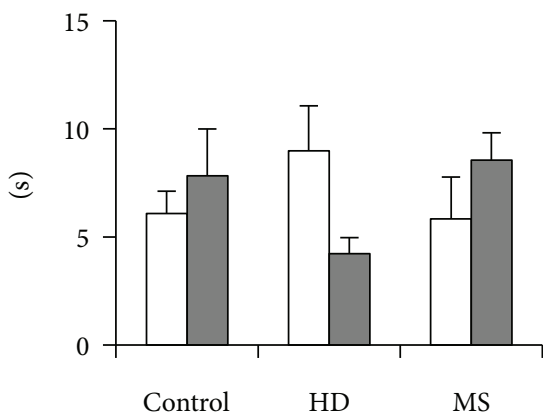

Rearing

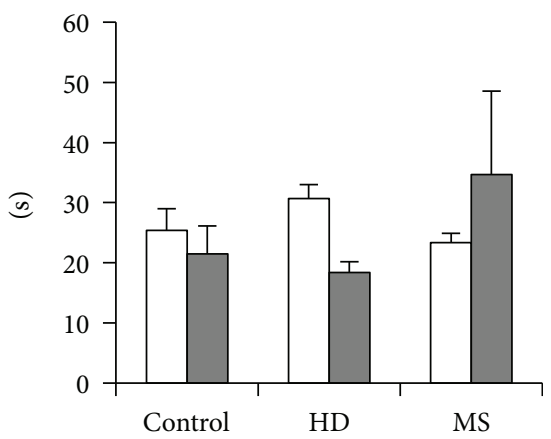

Figure 5: The influence of early-life stress on the behavior of adult female mice in open-field test in different phases of estrous cycle. Data present as mean \pm standard error of the mean (SEM). White box: estrus ( 5 female controls, 2 HD group, and 5 MS group), gray box: diestrus (6 female controls, $4 \mathrm{HD}$ group, and 3 MS group). Insufficient number of mice in each phase did not allow a correct statistical analysis.
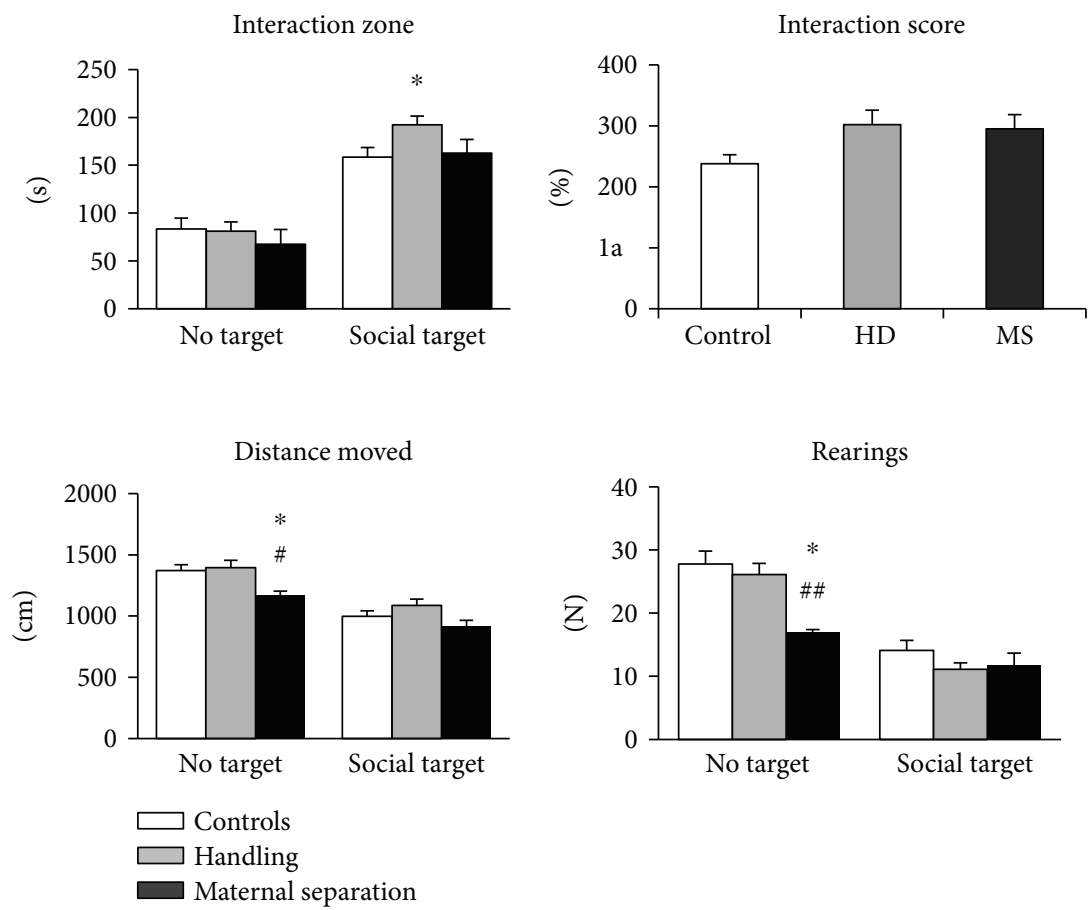

FIGURE 6: Effects of early-life stress on the social behavior of adult male mice. Handling have increased sociability of males, whereas maternal separation had no effects on social behavior. Data present as mean \pm standard error of the mean (SEM). White box: controls (males, $n=11$ ); grey box: HD (males, $n=10$ ), black box: MS (males, $n=6$ ); no target: the adaptation trial with an empty target box; social target: the interaction trial with an unfamiliar partner in the target box. ${ }^{*} p<0.05$ compared to controls; ${ }^{\#} p<0.05$; ${ }^{\# \#} p<0.01$ compared to HD. 

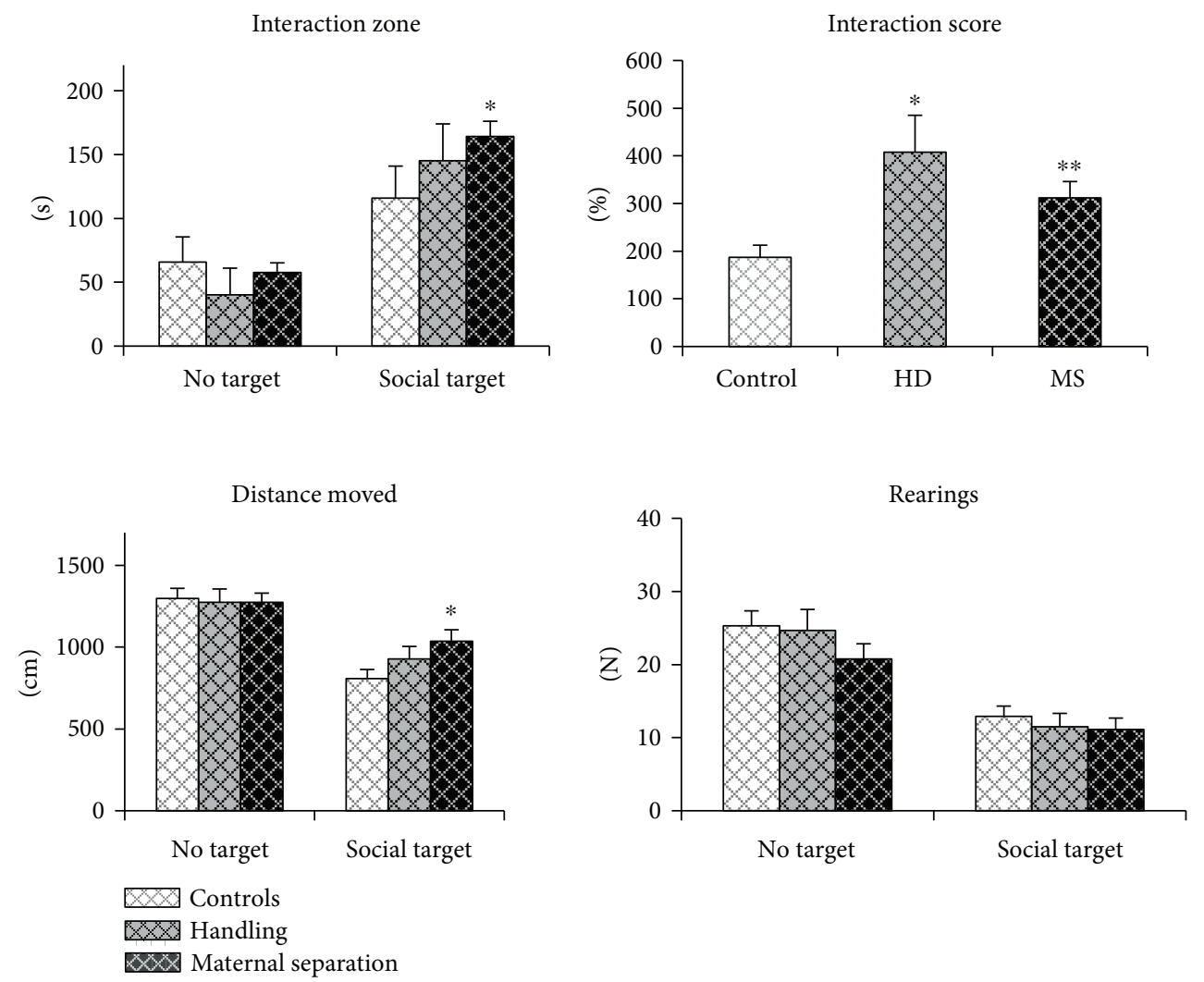

Figure 7: Effects of early-life stress on the social behavior of adult female mice. Both stressed females groups increased sociability in the test. Data present as mean \pm standard error of the mean (SEM). White box: controls (females $n=11$ ); grey box: HD (females $n=6$ ), black box: MS (females $n=8$ ); no target: the adaptation trial with an empty target box; social target: the interaction trial with an unfamiliar partner in the target box. ${ }^{*} p<0.05,{ }^{* *} p<0.01$ compared to controls.
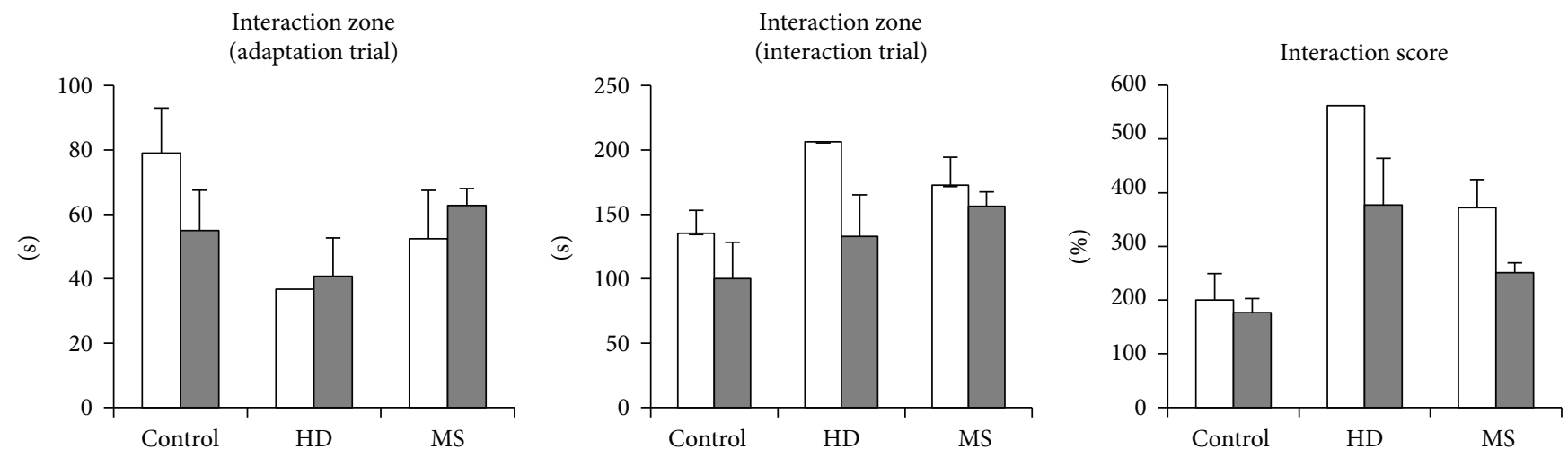

FIGURE 8: The influence of early-life stress on the behavior of adult female mice in social interaction test in different phases of estrous cycle. Data present as mean \pm standard error of the mean (SEM). White box: estrus (5 control females, 1 HD group, and 4 MS group), gray box: diestrus (6 control females, $5 \mathrm{HD}$ group, and $4 \mathrm{MS}$ group). Insufficient number of mice in each phase did not allow a correct statistical analysis.

According to a systematic review [18], female studies nearly always show positive or deleterious effects of early stress on anxiety, depressiveness, or cognitive functions, while male studies do not reveal significant effects of stress on these psychoemotional traits in about $30 \%$ of cases. The analysis of maternal separation consequences [18] suggests that, in most (but not all) cases, stress results in higher anxiety and cognitive deterioration in both males and females. However, a sex-specific difference is sometimes observed in the studies. The study by Romeo and colleagues [27] showed opposite changes in the locomotor activity of males and females, and another study [28] identified contrasting changes in aggressive behavior. Increased social behavior after maternal separation that we have discovered 
is typical of females only, while males have the same reaction to the partner as controls. Notably, brief separation has the same effect on social behavior both in males and females. Thus, the influence of early-life stress on behavior in adulthood is gender-dependent.

Multiple studies in sex hormone effects on emotional behavior and stress response $[80,81]$ suggest that estrous cycle should be taken into account in female experiments. Although emotional behavior and especially the level of anxiety in females are sensitive to the level of sex hormones $[82,83]$, only few studies on female behavior after early-life stress $[27,84]$ take into account the phase of the estrous cycle. Most researchers believe that daily vaginal smears are too stressful for animals or that the selections of females used in the studies are insufficiently representative to analyze $[25,28-30]$. However, studies often find no correlation between behavior and cycle phase $[85,86]$. The reason may be that hormonal influence is not very strong, and the stress of testing hides possible behavior dependence on hormones. We have not detected an influence of cycle phase on the behavioral traits studied. Proper statistical analysis was impeded by a low number of animals in the groups. However, the direction of change was the same in the estrous and diestrous phases, that is, hormonal level had an insignificant effect on emotional behavior, locomotor, and exploratory activity.

\section{Conclusion}

Thus, the present study shows that the social and individual behavior of adult mice can be modified by early-life events in a sex-specific manner. We have found no changes in the anxiety or social behavior of MS males. Disrupted individual behavior has been the only consequence of early stress. The intensity of stress may have been insufficient to produce later effects in males. Females have been more sensitive to stress. Maternal separation has led to increased female anxiety and social behavior. Brief separation of pups from their mothers resulted in positive behavioral changes in males and females. Both sexes had increased social behavior, and males had decreased anxiety, which confirms the hypothesis that mild early-life stress has a positive effect on later emotional behavior.

\section{Conflicts of Interest}

The authors declare that there are no conflicts of interests regarding the publication of this paper.

\section{Acknowledgments}

This work was supported by the Russian Science Foundation [Grant no. 16-15-10131]. The authors thank Pavlov K.S. (Laboratory of Experimental Models of Neurodegenerative Processes, Institute of Physiology and Basic Medicine, Novosibirsk, Russia) for his technical assistance with EthoVision XT, v.10.0.

\section{References}

[1] J. G. Johnson, P. Cohen, M. S. Gould, S. Kasen, J. Brown, and J. S. Brook, "Childhood adversities, interpersonal difficulties, and risk for suicide attempts during late adolescence and early adulthood," Archives of General Psychiatry, vol. 59, no. 8, pp. 741-749, 2002.

[2] A. M. Vaiserman, "Epigenetic programming by early-life stress: evidence from human populations," Developmental Dynamics, vol. 244, no. 3, pp. 254-265, 2015.

[3] F. Varese, F. Smeets, M. Drukker et al., "Childhood adversities increase the risk of psychosis: a meta-analysis of patientcontrol, prospective- and cross-sectional cohort studies," Schizophrenia Bulletin, vol. 38, no. 4, pp. 661-671, 2012.

[4] C. Heim, P. M. Plotsky, and C. B. Nemeroff, "Importance of studying the contributions of early adverse experience to neurobiological findings in depression," Neuropsychopharmacology, vol. 29, no. 4, pp. 641-648, 2004.

[5] H. J. Krugers and M. Joels, "Long-lasting consequences of early life stress on brain structure, emotion and cognition," Current Topics in Behavioral Neurosciences, vol. 18, pp. 81-92, 2014.

[6] M. H. Teicher, A. Tomoda, and S. L. Andersen, "Neurobiological consequences of early stress and childhood maltreatment: are results from human and animal studies comparable?," Annals of the New York Academy of Sciences, vol. 1071, no. 1, pp. 313-323, 2006.

[7] M. Vythilingam, C. Heim, J. Newport et al., "Childhood trauma associated with smaller hippocampal volume in women with major depression," The American Journal of Psychiatry, vol. 159, no. 12, pp. 2072-2080, 2002.

[8] A. L. van Harmelen, P. J. de Jong, K. A. Glashouwer, P. Spinhoven, B. W. Penninx, and B. M. Elzinga, "Child abuse and negative explicit and automatic self-associations: the cognitive scars of emotional maltreatment," Behaviour Research and Therapy, vol. 48, no. 6, pp. 486-494, 2010.

[9] U. Rao, L. A. Chen, A. S. Bidesi, M. U. Shad, M. A. Thomas, and C. L. Hammen, "Hippocampal changes associated with early-life adversity and vulnerability to depression," Biological Psychiatry, vol. 67, no. 4, pp. 357-364, 2010.

[10] M. H. Teicher, C. M. Anderson, and A. Polcari, "Childhood maltreatment is associated with reduced volume in the hippocampal subfields CA3, dentate gyrus, and subiculum," Proceedings of the National Academy of Sciences of the United States of America, vol. 109, no. 9, pp. E563-E572, 2012.

[11] A. Danese and B. S. McEwen, "Adverse childhood experiences, allostasis, allostatic load, and age-related disease," Physiology \& Behavior, vol. 106, no. 1, pp. 29-39, 2012.

[12] P. Dawes, K. J. Cruickshanks, D. R. Moore et al., "The effect of prenatal and childhood development on hearing, vision and cognition in adulthood," PLoS One, vol. 10, no. 8, article e0136590, 2015.

[13] A. Chocyk, B. Bobula, D. Dudys et al., "Early-life stress affects the structural and functional plasticity of the medial prefrontal cortex in adolescent rats," The European Journal of Neuroscience, vol. 38, no. 1, pp. 2089-2107, 2013.

[14] M. Rincel, A. L. Lepinay, Y. Janthakhin et al., "Maternal high-fat diet and early life stress differentially modulate spine density and dendritic morphology in the medial prefrontal cortex of juvenile and adult rats," Brain Structure and Function, 2017.

[15] Y. Janthakhin, M. Rincel, A. M. Costa, M. Darnaudery, and G. Ferreira, "Maternal high-fat diet leads to hippocampal and 
amygdala dendritic remodeling in adult male offspring," Psychoneuroendocrinology, vol. 83, pp. 49-57, 2017.

[16] N. P. Bondar and T. I. Merkulova, "Brain-derived neurotrophic factor and early-life stress: multifaceted interplay," Journal of Biosciences, vol. 41, no. 4, pp. 751-758, 2016.

[17] I. Herpfer, H. Hezel, W. Reichardt et al., "Early life stress differentially modulates distinct forms of brain plasticity in young and adult mice," PLoS One, vol. 7, no. 10, article e46004, 2012.

[18] S. G. Tractenberg, M. L. Levandowski, L. A. de Azeredo et al., "An overview of maternal separation effects on behavioural outcomes in mice: evidence from a four-stage methodological systematic review," Neuroscience \& Biobehavioral Reviews, vol. 68, pp. 489-503, 2016.

[19] A. Kaffman and M. J. Meaney, "Neurodevelopmental sequelae of postnatal maternal care in rodents: clinical and research implications of molecular insights," Journal of Child Psychology and Psychiatry, vol. 48, no. 3-4, pp. 224-244, 2007.

[20] E. R. de Kloet, R. M. Sibug, F. M. Helmerhorst, and M. V. Schmidt, "Stress, genes and the mechanism of programming the brain for later life," Neuroscience \& Biobehavioral Reviews, vol. 29, no. 2, pp. 271-281, 2005.

[21] S. Levine, "Influence of psychological variables on the activity of the hypothalamic-pituitary-adrenal axis," European Journal of Pharmacology, vol. 405, no. 1-3, pp. 149-160, 2000.

[22] C. R. Pryce and J. Feldon, "Long-term neurobehavioural impact of the postnatal environment in rats: manipulations, effects and mediating mechanisms," Neuroscience \& Biobehavioral Reviews, vol. 27, no. 1-2, pp. 57-71, 2003.

[23] M. V. Schmidt, "Molecular mechanisms of early life stress-lessons from mouse models," Neuroscience \& Biobehavioral Reviews, vol. 34, no. 6, pp. 845-852, 2010.

[24] G. Biagini and E. M. Pich, "Corticosterone administration to rat pups, but not maternal separation, affects sexual maturation and glucocorticoid receptor immunoreactivity in the testis," Pharmacology, Biochemistry, and Behavior, vol. 73, no. 1, pp. 95-103, 2002.

[25] R. A. Millstein and A. Holmes, "Effects of repeated maternal separation on anxiety- and depression-related phenotypes in different mouse strains," Neuroscience \& Biobehavioral Reviews, vol. 31, no. 1, pp. 3-17, 2007.

[26] M. Mehta and C. Schmauss, "Strain-specific cognitive deficits in adult mice exposed to early life stress," Behavioral Neuroscience, vol. 125, no. 1, pp. 29-36, 2011.

[27] R. D. Romeo, A. Mueller, H. M. Sisti, S. Ogawa, B. S. McEwen, and W. G. Brake, "Anxiety and fear behaviors in adult male and female C57BL/6 mice are modulated by maternal separation," Hormones and Behavior, vol. 43, no. 5, pp. 561-567, 2003.

[28] A. H. Veenema, R. Bredewold, and I. D. Neumann, “Opposite effects of maternal separation on intermale and maternal aggression in C57BL/6 mice: link to hypothalamic vasopressin and oxytocin immunoreactivity," Psychoneuroendocrinology, vol. 32, no. 5, pp. 437-450, 2007.

[29] M. Kundakovic, S. Lim, K. Gudsnuk, and F. A. Champagne, "Sex-specific and strain-dependent effects of early life adversity on behavioral and epigenetic outcomes," Frontiers in Psychiatry, vol. 4, p. 78, 2013.

[30] J. D. Bailoo, R. L. Jordan, X. J. Garza, and A. N. Tyler, "Brief and long periods of maternal separation affect maternal behavior and offspring behavioral development in C57BL/6 mice," Developmental Psychobiology, vol. 56, no. 4, pp. 674-685, 2014.

[31] M. C. Tsuda and S. Ogawa, "Long-lasting consequences of neonatal maternal separation on social behaviors in ovariectomized female mice," PLoS One, vol. 7, no. 3, article e33028, 2012.

[32] H. M. Savignac, T. G. Dinan, and J. F. Cryan, "Resistance to early-life stress in mice: effects of genetic background and stress duration," Frontiers in Behavioral Neuroscience, vol. 5, p. 13, 2011.

[33] E. Binder, K. Malki, J. L. Paya-Cano et al., "Antidepressants and the resilience to early-life stress in inbred mouse strains," Pharmacogenetics and Genomics, vol. 21, no. 12, pp. 779789, 2011.

[34] J. J. Dimatelis, I. M. Vermeulen, K. Bugarith, D. J. Stein, and V. A. Russell, "Female rats are resistant to developing the depressive phenotype induced by maternal separation stress," Metabolic Brain Disease, vol. 31, no. 1, pp. 109-119, 2016.

[35] E. D. George, K. A. Bordner, H. M. Elwafi, and A. A. Simen, "Maternal separation with early weaning: a novel mouse model of early life neglect," BMC Neuroscience, vol. 11, no. 1, p. 123, 2010.

[36] B. C. Carlyle, A. Duque, R. R. Kitchen et al., "Maternal separation with early weaning: a rodent model providing novel insights into neglect associated developmental deficits," Development and Psychopathology, vol. 24, no. 04, pp. 14011416, 2012.

[37] I. Gracia-Rubio, M. Moscoso-Castro, O. J. Pozo, J. Marcos, R. Nadal, and O. Valverde, "Maternal separation induces neuroinflammation and long-lasting emotional alterations in mice," Progress in Neuro-Psychopharmacology and Biological Psychiatry, vol. 65, pp. 104-117, 2016.

[38] A. Lin, S. J. Wood, and A. R. Yung, "Measuring psychosocial outcome is good," Current Opinion in Psychiatry, vol. 26, no. 2, pp. 138-143, 2013.

[39] E. Ognibene, W. Adriani, A. Caprioli et al., "The effect of early maternal separation on brain derived neurotrophic factor and monoamine levels in adult heterozygous reeler mice," Progress in Neuro-Psychopharmacology and Biological Psychiatry, vol. 32, no. 5, pp. 1269-1276, 2008.

[40] M. C. Tsuda, N. Yamaguchi, and S. Ogawa, "Early life stress disrupts peripubertal development of aggression in male mice," Neuroreport, vol. 22, no. 6, pp. 259-263, 2011.

[41] T. B. Franklin, N. Linder, H. Russig, B. Thony, and I. M. Mansuy, "Influence of early stress on social abilities and serotonergic functions across generations in mice," PLoS One, vol. 6, no. 7, article e21842, 2011.

[42] M. R. Farrell, F. H. Holland, R. M. Shansky, and H. C. Brenhouse, "Sex-specific effects of early life stress on social interaction and prefrontal cortex dendritic morphology in young rats," Behavioural Brain Research, vol. 310, pp. 119-125, 2016.

[43] H. J. Hulshof, A. Novati, A. Sgoifo, P. G. Luiten, J. A. den Boer, and P. Meerlo, "Maternal separation decreases adult hippocampal cell proliferation and impairs cognitive performance but has little effect on stress sensitivity and anxiety in adult Wistar rats," Behavioural Brain Research, vol. 216, no. 2, pp. 552-560, 2011.

[44] M. Niwa, Y. Matsumoto, A. Mouri, N. Ozaki, and T. Nabeshima, "Vulnerability in early life to changes in the 
rearing environment plays a crucial role in the aetiopathology of psychiatric disorders," The International Journal of Neuropsychopharmacology, vol. 14, no. 04, pp. 459-477, 2011.

[45] M. J. Meaney, "Maternal care, gene expression, and the transmission of individual differences in stress reactivity across generations," Annual Review of Neuroscience, vol. 24, no. 1, pp. 1161-1192, 2001.

[46] D. B. Parfitt, J. R. Walton, E. A. Corriveau, and D. L. Helmreich, "Early life stress effects on adult stress-induced corticosterone secretion and anxiety-like behavior in the C57BL/6 mouse are not as robust as initially thought," Hormones and Behavior, vol. 52, no. 4, pp. 417-426, 2007.

[47] A. Luchetti, D. Oddi, V. Lampis et al., "Early handling and repeated cross-fostering have opposite effect on mouse emotionality," Frontiers in Behavioral Neuroscience, vol. 9, p. 93, 2015.

[48] R. G. Lister, "The use of a plus-maze to measure anxiety in the mouse," Psychopharmacology, vol. 92, no. 2, pp. 180-185, 1987.

[49] R. J. Rodgers and J. C. Cole, "Influence of social isolation, gender, strain, and prior novelty on plus-maze behaviour in mice," Physiology \& Behavior, vol. 54, no. 4, pp. 729-736, 1993.

[50] O. Friard and M. Gamba, "BORIS: a free, versatile open-source event-logging software for video/audio coding and live observations," Methods in Ecology and Evolution, vol. 7, no. 11, pp. 1325-1330, 2016.

[51] S. Macri and G. Laviola, "Single episode of maternal deprivation and adult depressive profile in mice: interaction with cannabinoid exposure during adolescence," Behavioural Brain Research, vol. 154, no. 1, pp. 231-238, 2004.

[52] D. B. Parfitt, J. K. Levin, K. P. Saltstein, A. S. Klayman, L. M. Greer, and D. L. Helmreich, "Differential early rearing environments can accentuate or attenuate the responses to stress in male C57BL/6 mice," Brain Research, vol. 1016, no. 1, pp. 111-118, 2004.

[53] H. Toda, S. Boku, S. Nakagawa et al., "Maternal separation enhances conditioned fear and decreases the mRNA levels of the neurotensin receptor 1 gene with hypermethylation of this gene in the rat amygdala," PLoS One, vol. 9, no. 5, article e97421, 2014.

[54] I. C. Weaver, M. J. Meaney, and M. Szyf, "Maternal care effects on the hippocampal transcriptome and anxiety-mediated behaviors in the offspring that are reversible in adulthood," Proceedings of the National Academy of Sciences of the United States of America, vol. 103, no. 9, pp. 3480-3485, 2006.

[55] J. Lehmann and J. Feldon, "Long-term biobehavioral effects of maternal separation in the rat: consistent or confusing?," Reviews in the Neurosciences, vol. 11, no. 4, pp. 383-408, 2000.

[56] G. Biagini, E. M. Pich, C. Carani, P. Marrama, and L. F. Agnati, "Postnatal maternal separation during the stress hyporesponsive period enhances the adrenocortical response to novelty in adult rats by affecting feedback regulation in the CA1 hippocampal field," International Journal of Developmental Neuroscience, vol. 16, no. 3-4, pp. 187-197, 1998.

[57] P. M. Plotsky and M. J. Meaney, "Early, postnatal experience alters hypothalamic corticotropin-releasing factor (CRF) mRNA, median eminence CRF content and stress-induced release in adult rats," Molecular Brain Research, vol. 18, no. 3, pp. 195-200, 1993.

[58] M. Lippmann, A. Bress, C. B. Nemeroff, P. M. Plotsky, and L. M. Monteggia, "Long-term behavioural and molecular alterations associated with maternal separation in rats," The European Journal of Neuroscience, vol. 25, no. 10, pp. 3091-3098, 2007.

[59] C. O. Ladd, R. L. Huot, K. V. Thrivikraman, C. B. Nemeroff, and P. M. Plotsky, "Long-term adaptations in glucocorticoid receptor and mineralocorticoid receptor mRNA and negative feedback on the hypothalamo-pituitary-adrenal axis following neonatal maternal separation," Biological Psychiatry, vol. 55, no. 4, pp. 367-375, 2004.

[60] S. Navailles, R. Zimnisky, and C. Schmauss, "Expression of glucocorticoid receptor and early growth response gene 1 during postnatal development of two inbred strains of mice exposed to early life stress," Developmental Neuroscience, vol. 32, no. 2, pp. 139-148, 2010.

[61] S. E. File and J. R. Hyde, "Can social interaction be used to measure anxiety?," British Journal of Pharmacology, vol. 62, no. 1, pp. 19-24, 1978.

[62] D. Drai, N. Kafkafi, Y. Benjamini, G. Elmer, and I. Golani, "Rats and mice share common ethologically relevant parameters of exploratory behavior," Behavioural Brain Research, vol. 125, no. 1-2, pp. 133-140, 2001.

[63] E. Fonio, Y. Benjamini, and I. Golani, "Short and long term measures of anxiety exhibit opposite results," PLoS One, vol. 7, no. 10, article e48414, 2012.

[64] D. F. Avgustinovich, T. V. Lipina, N. P. Bondar, O. V. Alekseyenko, and N. N. Kudryavtseva, "Features of the genetically defined anxiety in mice," Behavior Genetics, vol. 30, no. 2, pp. 101-109, 2000.

[65] G. Griebel, C. Belzung, R. Misslin, and E. Vogel, "The free-exploratory paradigm: an effective method for measuring neophobic behaviour in mice and testing potential neophobiareducing drugs," Behavioural Pharmacology, vol. 4, no. 6, pp. 637-644, 1993.

[66] N. N. Kudryavtseva, N. P. Bondar, and D. F. Avgustinovich, "Association between experience of aggression and anxiety in male mice," Behavioural Brain Research, vol. 133, no. 1, pp. 83-93, 2002.

[67] T. V. Lipina and N. N. Kudriavtseva, "The study of exploratory behavior in CBA/Lac male mice under influence of positive and negative social interactions," Zhurnal Vyssher Nervno Deiatelnosti Imeni I P Pavlova, vol. 58, no. 2, pp. 194-201, 2008.

[68] D. M. Lyons, K. J. Parker, and A. F. Schatzberg, "Animal models of early life stress: implications for understanding resilience," Developmental Psychobiology, vol. 52, no. 5, pp. 402-410, 2010.

[69] Y. Bian, L. Yang, Z. Wang, Q. Wang, L. Zeng, and G. Xu, "Repeated three-hour maternal separation induces depression-like behavior and affects the expression of hippocampal plasticity-related proteins in C57BL/6N mice," Neural Plasticity, vol. 2015, Article ID 627837, 7 pages, 2015.

[70] H. C. Atkinson and B. J. Waddell, "Circadian variation in basal plasma corticosterone and adrenocorticotropin in the rat: sexual dimorphism and changes across the estrous cycle," Endocrinology, vol. 138, no. 9, pp. 3842-3848, 1997.

[71] A. Iwasaki-Sekino, A. Mano-Otagiri, H. Ohata, N. Yamauchi, and T. Shibasaki, "Gender differences in corticotropin and corticosterone secretion and corticotropin-releasing factor mRNA expression in the paraventricular nucleus of the hypothalamus and the central nucleus of the amygdala in response 
to footshock stress or psychological stress in rats," Psychoneuroendocrinology, vol. 34, no. 2, pp. 226-237, 2009.

[72] G. L. Hermes, L. Rosenthal, A. Montag, and M. K. McClintock, "Social isolation and the inflammatory response: sex differences in the enduring effects of a prior stressor," American Journal of Physiology. Regulatory, Integrative and Comparative Physiology, vol. 290, no. 2, pp. R273-R282, 2006.

[73] I. Kloehn, S. B. Pillai, L. Officer, C. Klement, P. J. Gasser, and J. A. Evans, "Sexual differentiation of circadian clock function in the adrenal gland," Endocrinology, vol. 157, no. 5, pp. 1895-1904, 2016.

[74] R. Verma, Y. P. Balhara, and C. S. Gupta, "Gender differences in stress response: role of developmental and biological determinants," Industrial Psychiatry Journal, vol. 20, no. 1, pp. 4-10, 2011.

[75] R. Shepard, C. E. Page, and L. Coutellier, "Sensitivity of the prefrontal GABAergic system to chronic stress in male and female mice: relevance for sex differences in stress-related disorders," Neuroscience, vol. 332, pp. 1-12, 2016.

[76] G. E. Hodes, M. L. Pfau, I. Purushothaman et al., "Sex differences in nucleus accumbens transcriptome profiles associated with susceptibility versus resilience to subchronic variable stress," The Journal of Neuroscience, vol. 35, no. 50, pp. 16362-16376, 2015.

[77] D. F. Avgustinovich, I. L. Kovalenko, and L. A. Koryakina, "Effects of single episodes of severe stress on the behavior of male and female CBA/Lac and C57BL/6J mice," Neuroscience and Behavioral Physiology, vol. 37, no. 7, pp. 731-737, 2007.

[78] M. Q. Steinman, N. Duque-Wilckens, G. D. Greenberg et al., "Sex-specific effects of stress on oxytocin neurons correspond with responses to intranasal oxytocin," Biological Psychiatry, vol. 80, no. 5, pp. 406-414, 2016.

[79] B. C. Trainor, M. C. Pride, R. Villalon Landeros et al., "Sex differences in social interaction behavior following social defeat stress in the monogamous California mouse (Peromyscus californicus)," PLoS One, vol. 6, no. 2, article e17405, 2011.

[80] J. P. ter Horst, E. R. de Kloet, H. Schachinger, and M. S. Oitzl, "Relevance of stress and female sex hormones for emotion and cognition," Cellular and Molecular Neurobiology, vol. 32, no. 5, pp. 725-735, 2012.

[81] P. Palanza, L. Gioiosa, and S. Parmigiani, "Social stress in mice: gender differences and effects of estrous cycle and social dominance," Physiology \& Behavior, vol. 73, no. 3, pp. 411420, 2001.

[82] A. A. Walf and C. A. Frye, "Estradiol decreases anxiety behavior and enhances inhibitory avoidance and gestational stress produces opposite effects," Stress, vol. 10, no. 3, pp. 251-260, 2007.

[83] F. K. Marcondes, K. J. Miguel, L. L. Melo, and R. C. SpadariBratfisch, "Estrous cycle influences the response of female rats in the elevated plus-maze test," Physiology \& Behavior, vol. 74, no. 4-5, pp. 435-440, 2001.

[84] R. W. Rhees, E. D. Lephart, and D. Eliason, "Effects of maternal separation during early postnatal development on male sexual behavior and female reproductive function," Behavioural Brain Research, vol. 123, no. 1, pp. 1-10, 2001.
[85] H. Meziane, A. M. Ouagazzal, L. Aubert, M. Wietrzych, and W. Krezel, "Estrous cycle effects on behavior of C57BL/6J and BALB/cByJ female mice: implications for phenotyping strategies," Genes, Brain, and Behavior, vol. 6, no. 2, pp. 192-200, 2007.

[86] J. P. Ter Horst, J. Kentrop, M. Arp, C. J. Hubens, E. R. de Kloet, and M. S. Oitzl, "Spatial learning of female mice: a role of the mineralocorticoid receptor during stress and the estrous cycle," Frontiers in Behavioral Neuroscience, vol. 7, p. 56, 2013. 


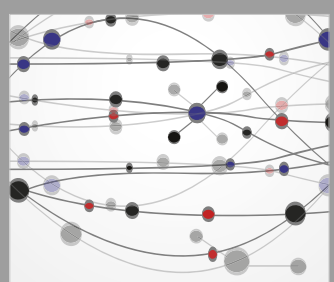

The Scientific World Journal
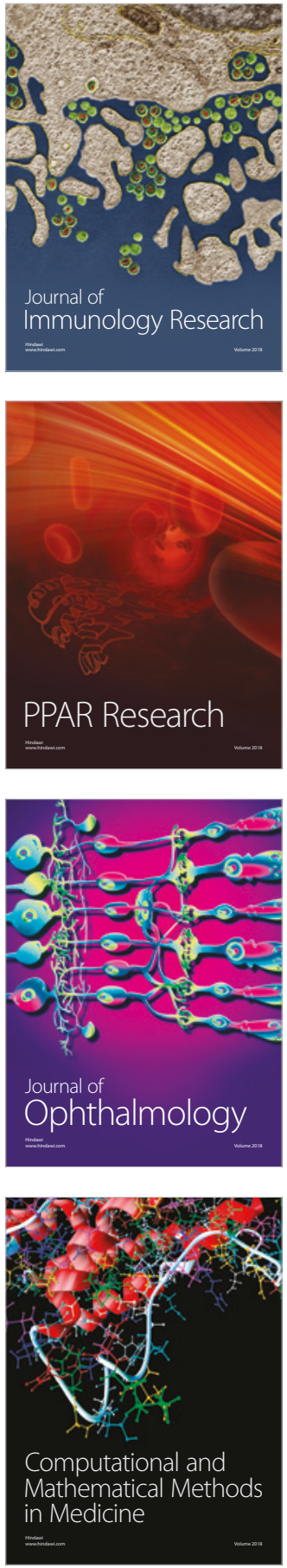

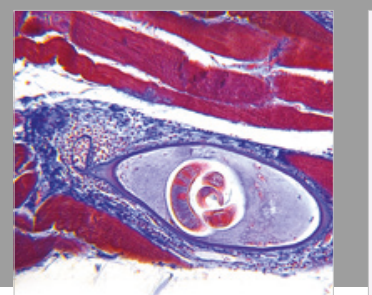

Gastroenterology Research and Practice

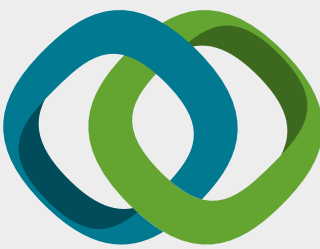

\section{Hindawi}

Submit your manuscripts at

www.hindawi.com
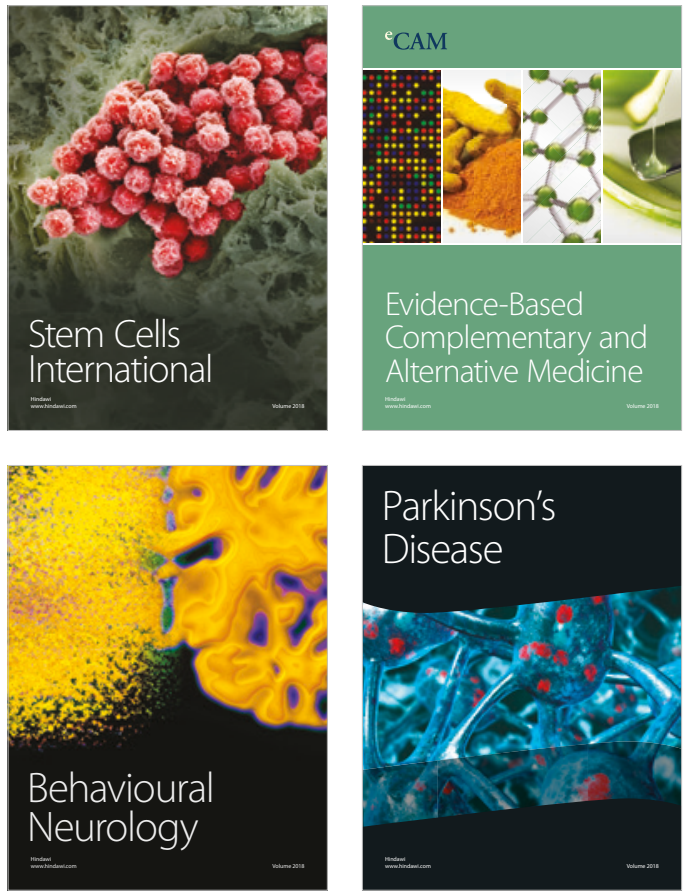

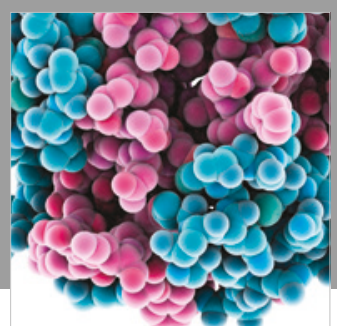

ournal of

Diabetes Research

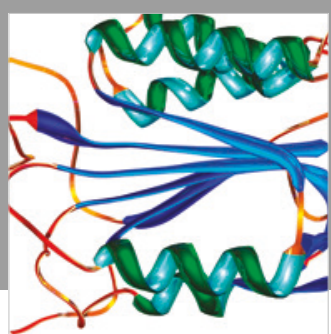

Disease Markers
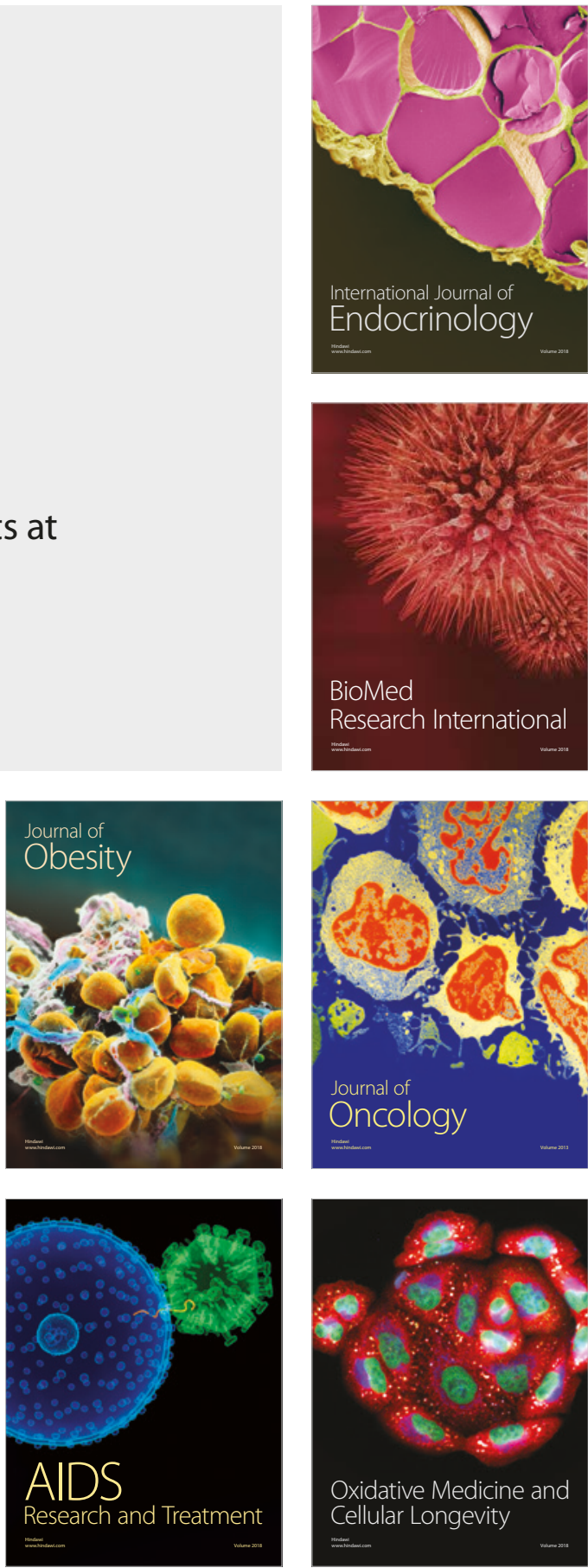